\title{
ANALISIS PENDAPATAN PETANI PADI SAWAH DI DESA KUALA MULIA KECAMATAN KUALA CENAKU KABUPATEN INDRAGIRI HULU
}

\author{
Oleh
}

\author{
Irawati \\ Sekolah Tinggi Ilmu Ekonomi Indragiri (STIE-I) Rengat \\ Email: irawati@stieindragiri.ac.id
}

\begin{abstract}
This research was conducted in Kuala Mulia Village, Kuala Cenaku sub-District of Indragiri Hulu Regency. The purpose of this research was to determine the factors that affect income of the rice farmers in Kuala Mulia Village. In this research the author took data with technical observation, interviews and documentation. And to analyze data quantitatively. By calculating revenues, rice farmers' costs and income then analyzes the business feasibility of the $R / C$ ratio. The results of the analysis obtained the acceptance of the rice farmers group was Rp.6,457,500,000, while the total cost was Rp.2,650,445,000. The income of rice farmers is $R p .3,807,055,000$. And the $R / C$ ratio analysis was obtained at 2,443 which means this business is feasible to be developed.
\end{abstract}

Keywords: Total Revenue,Total Costs, Price, Product

\begin{abstract}
ABSTRAK
Penelitian ini dilaksanakan di Desa Kuala Mulia Kecamatan Kuala Cenaku Kabupaten Indragiri Hulu. Adapun tujuan penelitian ini adalah untuk mengetahui faktor-faktor yang mempengaruhi pendapatan petani padi sawah di Desa Kuala Mulia. Dalam penelitian ini penulis mengambil data dengan teknis observasi, wawancara dan dokumentasi. Dan menganalisa data secara kuantitatif. Dengan menghitung penerimaan, biaya-biaya petani padi dan pendapatannya kemudian analisis kelayakan usaha $R / C$ Rasio. Hasil analisis diperoleh penerimaan kelompok petani padi adalah Rp.6.457.500.000,- sedangkan total biaya adalah Rp.2.650.445.000. Pendapatan petani padi adalah Rp.3.807.055.000,-. Dan analisis $R / C$ Rasio diperoleh sebesar 2,443 yang berarti usaha ini layak untuk dikembangkan.
\end{abstract}

Kata Kunci : Total Penerimaan, Total Biaya, Harga jual, Jumlah Produksi 


\section{PENDAHULUAN}

Pembangunan pertanian penting dalam memaksimalkan pemanfaatan geografi dan kekayaan alam Indonesia, memadukannya dengan teknologi agar mampu memperoleh hasil sesuai dengan yang diharapkan. Sektor pertanian berperan penting dalam menyediakan bahan pangan bagi seluruh penduduk maupun menyediakan bahan baku bagi industri, dan untuk perdagangan ekspor (Wisma, 2012).

Penyediaan lapangan kerja, penyediaan penganekaragaman menu makan, kontribusinya untuk mengurangi jumlah orang-orang miskin di pedesaan dan peranannya terhadap nilai devisa yang dihasilkan dari ekspor (Soekartawi, 2010).

Menurut Laporan Kementrian Pertaninan bahwa sepuluh Daerah penghasil padi terbesar di Indonesia dalam jutaan Ton adalah sebagai berikut .

Tabel 1.1 : Propinsi penghasil padi terbesar di Indonesia pada tahun 2017.

\begin{tabular}{|c|l|c|}
\hline NO. & \multicolumn{1}{|c|}{ DAERAH } & VOL. PRODUKSI \\
\hline 1 & Jawa Timur & 13,13 \\
\hline 2 & Jawa Barat & 12,52 \\
\hline 3 & Jawa Tengah & 11,42 \\
\hline 4 & Sulawesi Selatan & 6 \\
\hline 5 & Sumatera Utara & 5,1 \\
\hline 6 & Sumatera Selatan & 4,8 \\
\hline 7 & Lampung & 4,3 \\
\hline 8 & Sumatera Barat & 2,8 \\
\hline 9 & Aceh & 2,7 \\
\hline 10 & Kalimantan Selatan & 2,4 \\
\hline
\end{tabular}

Sumber : Kementrian Pertanian

Dari Tabel di atas, Jawa Timur sebagai daerah penghasil tertinggi sebesar 13,13 juta ton atau setara dengan 16,1 \% produksi secara Nasional. Jawa Barat mampu memproduksi 13,52 juta ton atau setara dengan 15,38 \% dari produksi Nasional. Kemudian Jawa Tengah mendapat urutan ketiga dengan produksi sejumlah 11,42 juta Ton pada tahun 2017 atau setara dengan $14 \%$ produksi padi Nasional.

Berdasarkan data tersebut di atas, memang daerah Riau belum termasuk kedalam sepuluh besar daerah penghasil padi di Indonesia. Tetapi daerah Riau juga merupakan daerah penghasil padi. Desa Kuala Mulia merupakan salah satu Desa di Kabupaten Indragiri Hulu, Riau. Berikut ini akan penulis sajikan Luas lahan pertanian dan hasilnya di Desa Kuala Mulia. 
Volume VIII, No. 01, September 2019

Tabel. 1.2: Jumlah Petani. Luas lahan, dan hasil pertanian padi di Desa Kuala Mulia 2018

\begin{tabular}{|c|c|c|c|}
\hline Jumlah Petani & Kelompok Tani & Luas Lahan (Ha) & Hasil Gabah (Ton) \\
\hline 383 & 18 & 410 & 1.435 \\
\hline
\end{tabular}

Sumber : Data olahan

Dari Tabel. 1.2 dapat diketahui bahwa rata-rata lahan pertanian menghasilkan gabah sebanyak ${ }_{ \pm} 3,5$ Ton gabah / Ha untuk setiap kali panen.

Berdasarkan latar belakang masalah di atas, peneliti sangat tertarik untuk mengangkat judul penelitian : "analisis pendapatan petani padi sawah di desa Kuala Mulia kecamatan Kuala Cenaku kabupaten Indragiri Hulu".

\section{TELAAH PUSTAKA DAN HIPOTESIS}

\section{Padi sawah}

Pada umumnya petani tradisional menanam padi hanya berdasarkan pengalaman, dengan terbatasnya pengetahuan maka satu jenis padi ditanam terus menerus, dalam suatu lahan. Pola tanam yang demikian bukan cara yang baik, terutama terhadap kemungkinan besar serangan dan penyakit. Adapun jenis padi yang diusahakan oleh petani yaitu (Rosyidi, 1998) :

1) Padi sawah yaitu padi yang ditanam di sawah, yaitu lahan yang cukup memperoleh air. Padi sawah pada waktu tertentu memerlukan genangan air, termasuk sejak musim tanam sampai mulai berbuah.

2) Padi kering yaitu jenis padi yang tidak membutuhkan banyak air sebagaimana padi sawah. Bahkan padi kering ini dapat tumbuh hanya mengandalkan curah hujan.

\section{Konsep Usaha Tani}

Ilmu usaha tani adalah ilmu yang mempelajari bagaimana seseorang mengusahakan dan mengkoordinir faktor-faktor produksi berupa lahan dan alam sekitarnya sebagai modal sehingga memberikan manfaat yang sebaik-baiknya. Sebagai ilmu pengetahuan, ilmu usahatani merupakan ilmu yang mempelajari cara-cara petani menentukan, mengorganisasikan penggunaan faktor-faktor produksi seefektif dan seefisien mungkin, sehingga usaha tersebut memberikan pendapatan semaksimal mungkin. (Suratiyah, 2015) 
Usaha tani merupakan seluruh proses pengorganisasian faktor-faktor produksi yaitu alam, tenaga kerja, modal dan pengelolaan yang diusahakan oleh perorangan atau sekumpulan orang untuk menghasilkan output yang dapat memenuhi kebutuhan keluarga ataupun orang lain di samping bermotif mencari keuntungan. Pada umumnya ciri-ciri usaha tani di Indonesia adalah berlahan sempit, modal relative kecil, pengetahuan petani terbatas, kurang dinamik sehingga berakibat pada rendahnya pendapata usaha tani (Rahardjo, 2001).

\section{Biaya Usahatani}

Biaya usahatani adalah semua pengeluaran yang dinyatakan dengan uang yang diperlukan untuk menghasilkan sesuatu produk dalam suatu periode produksi . Nilai biaya dinyatakan dengan uang, yang termasuk dengan biaya adalah :

a. Sarana produksi yang habis terpakai seperti bibit, pupuk, pestisida, bahan bakar, bunga modal, dalam penanaman lain.

b. Lahan seperti sewa lahan baik berupa uang atau pajak, iuran pengairan, taksiran penggunaan biaya jika yang digunakan ialah tanah milik sendiri.

c. Biaya dari alat-alat produksi tahan lama, yaitu seperti bangunan, alat dan perkakas yang berupa penyusutan.

d. Tenaga kerja dari petani itu sendiri dan anggota keluarganya, tenaga kerja tetap atau tenaga bergaji tetap.

e. Biaya-biaya tak terduga lainnya. (Hutabarat, 1995)

Biaya adalah Sejumlah nilai uang yang dikeluarkan oleh produsen atau pengusaha untuk membiayai kegiatan produksi (Supardi, 2000).

Secara Matematika biaya dibedakan menjadi dua yakni biaya tetap (Fixed Cost) dan biaya variable (Variable Cost). Biaya Tetap adalah biaya yang harus atau tetap dikeluarkan walaupun tidak melakukan kegiatan, sedangkan Biaya Variabel adalah biaya yang dikeluarkan yang besarnya proporsional dengan kegiatan yang dilakukan. Berikut rumus fungsi biaya :

$\mathbf{T C}=\mathbf{F C}+\mathbf{V C}$

Keterangan :

$\mathrm{TC}=$ Biaya Total

$\mathrm{FC} \quad=$ Total Biaya Tetap

VC = Total Biaya Variabel (Sunyoto, 2011) 


\section{Penerimaan Usahatani}

Pendapatan usaha tani dibedakan atas pendapatan kotor dan pendapatan bersih, pendapatan kotor petani didefenisikan sebagai nilai produk total usaha tani dalam jangka waktu tertentu, baik yang dijual maupun yang tidak dijual (Soekartawi, 2002).

Pendapatan sering digunakan sebagai indikator pembangunan selain untuk membedakan tingkat kemajuan ekonomi antara Negara maju dengan Negara yang sedang berkembang (Arsyad, 2004).

Pendapatan adalah penghasilan berupa uang selama periode tertentu (Jhingan, 2003).

Keuntungan atau Laba adalah Penerimaan total dikurangi dengan Total biaya. Yang dapat dirumuskan sebagai berikut :

$$
\pi=T R-T C
$$

$$
\begin{aligned}
\text { Keterangan }: & \pi=\text { Laba } \\
& \text { TR }=\text { Total Penerimaan } \\
& \text { TC }=\text { Total Biaya (Sunyoto, 2011) }
\end{aligned}
$$

\section{Penelitian Terdahulu}

$\begin{array}{llc}\text { Nama } & \text { Variabel } & \text { Kesimpulan } \\ \text { 1. Fatmawati M.L (2013) } & \text { - Tingkat Produksi } & \text { - Besar kecilnya pen- } \\ & \text { - Pendapatan Bersih } & \text { dapatan yg diterima } \\ & \text { - Biaya Produksi } & \text { dipengaruhi oleh pe- } \\ & \text { - Biaya Variabel } & \text { nerimaan dan biaya } \\ \text { - Harga Produksi } & \text { produksi. Jika pro- } \\ \text { - R/C Ratio } & \text { duksi \& harga sema- } \\ & & \text { kin tinggi maka pe- } \\ \text { 2. Phahlevi. R (2013) } & \text { nerimaan akan me - } \\ & \text { Variabel } & \text { ningkat. } \\ \text { - Tingkat Pendapatan } & \text { - Harga jual padi, luas } \\ & \text { - Harga jual } & \text { lahan \& jmlh by ush } \\ \text { - Biaya usaha tani } & \text { tani berpengaruh thd } \\ \text { - Jumlah Produksi } & \text { jumlah produksi }\end{array}$


- Luas lahan, hrg jual

Jml produksi bpgrh

Terhadap pendapat-

an petani.

3. Suprayitno (2013)

Variabel
- Benih
- Pestisida
- Pupuk
- Tenaga Kerja

Kesimpulan

- Pupuk, benih, pesti

sida dan tenaga kerja

tidak berpengaruh

terhadap pendapatan

\section{Hipotesis}

Berdasarkan Uraian dan latar belakang permasalahan, rumusan masalah, dan telaah pustaka maka penulis dapat mengemukakan hipotesis atau jawaban sementara sebagai berikut :

a. Besaran penerimaan petani dalam usahatani padi sawah cukup besar di Desa Kulia Mulia.

b. Besaran biaya petani padi sawah masih relative kecil.

c. Usaha tani padi sawah layak untuk dikembangkan.

\section{Variabel Penelitian}

Dalam penelitian ini variabelnya adalah sebagai berikut :

- Penerimaan

- Harga jual

- Biaya usahatani

\section{METODE PENELITIAN}

\section{Tempat (lokasi) dan Waktu Penelitian}

Penulis melakukan penelitian langsung di Desa Kuala Mulia dengan waktu selama 3 bulan. 


\section{Jenis dan Sumber Data}

a. Penulis menggunakan sumber data adalah data primer dimana penulis memperoleh data langsung dari riset lapangan yang menjadi objek.

b. Penulis menggunakan Sumber data sekunder dimana datanya berkaitan dengan dasar teoritis diperoleh dari studi pustaka maupun data yang diperoleh langsung dari kantor Kepala Desa serta bahan-bahan lain yang diperlukan dalam pembahasan masalah.

\section{Metode Pengumpulan Data}

\section{a. Observasi}

Peneliti melakukan pengamatan lebih kurang selama 1 (satu) bulan yang mana tujuannya adalah untuk mendeskripsikan masalah yang diangkat dan aktivitasaktivitas yang sedang berlangsung. Penelitian ini dilakukan di Desa Kuala Mulia Kecamatan Kuala Cenaku Kabupatem Indragiri Hulu.

b. Wawancara

Dimana peneliti melakukan wawancara langsung kepada orang-orang yang berhubungan langsung dengan masalah ini. Jadi informasi yang diperoleh dari hasil wawancara dapat menjelaskan tentang suatu fenomena yang diangkat oleh peneliti.

c. Dokumentasi

Penulis memperoleh dalam hal-hal program kerja Desa dan berita lainnya. Penulis menggunakan penelitian lapangan (field research) dengan mengumpulkan data survei dengan penggunaan list dari pertanyaan-pertanyaan.

\section{Populasi dan sampel Penelitian}

Populasi merupakan wilayah generalisasi yang terdiri atas objek atau subjek yang mempunyai kualitas dan karakteristik tertentu (Sugiono, 2009).

Di dalam penelitian ini Populasinya adalah anggota masing-masing kelompok tani yang terdapat di Desa Kuala Mulia yang berjumlah sebanyak 18 kelompok tani.

\section{Analisis Data}

Penulis melakukan analisis sebagai berikut : 
a. Analisis Usahatani Padi

Yang meliputi analisis biaya usahatani, penerimaan usahatani dan pendapatan usahatani padi sawah.

b. Biaya Produksi Padi

Analisis biaya usahatani budidaya padi sawah memiliki komponen biaya usahatani yang terdiri atas biaya tetap dan biaya variabel, sebagai berikut :

1. Biaya tetap, yaitu biaya yang penggunaannya tidak habis dalam satu masaproduksi. Biaya tetap yang tergolong dalam kelompok ini antara lain : sewa tanah, biaya alat kerja, dan lain sebagainya.

2. Biaya Variabel, yaitu biaya yang besar kecilnya sangat tergantung pada skala produksi. Yang termasuk biaya variabel antara lain : benih, pupuk, pestisida, upah tenaga kerja, biaya panen, biaya pasca panen, biaya transportasi dan lain sebagainya.

$\mathrm{TC}=\mathrm{TFC}+\mathrm{TVC}$

Keterangan :

TC : Total Cost (Rp/Periode)

TFC : Total Fixed Cost (Rp/Periode)

TVC : Total Variabel Cost (Rp/Periode) (Dumairy, 2004)

c. Penerimaan Usahatani Padi

Pendapatan usahatani adalah selisih antara penerimaan dan semua biaya yang dikeluarkan. Pendapatan kotor atau penerimaan adalah nilai produksi komoditas pertanian secara keseluruhan sebelum dikurangi biaya produksi. Penerimaan dapat dirumuskan sebagai berikut :

$\mathrm{TR}=\mathrm{P} \times \mathrm{Q}$

$$
\begin{aligned}
\text { Keterangan }: \text { TR } & =\text { Penerimaan Total }(\mathrm{Rp} / \text { Periode }) \\
\mathrm{P} & =\text { Harga Jual }(\mathrm{Per} / \mathrm{Kg}) \\
\mathrm{Q} & =\text { Jumlah Produksi }(\mathrm{Kg})(\text { Sunyoto, } 2011)
\end{aligned}
$$

d. Pendapatan atau Keuntungan Usahatani Padi

Keuntungan bersih, yaitu seluruh pendapatan yang diperoleh petani dalam satu tahun dikurangi dengan biaya produksi selama proses produksi. Biaya produksi meliputi biaya riil tenaga kerja dan biaya riil sarana produksi. Keuntungan dapat dirumuskan sebagai berikut :

$$
\pi=\mathrm{TR}-\mathrm{TC}
$$

Keterangan : $\pi=$ Pendapatan/Keuntungan

$\mathrm{TR}=$ Total Revenue

$\mathrm{TC}=$ Total Cost (Sunyoto, 2011)

e. Analisis Kelayakan Usaha (R/C- Ratio)

$\mathrm{R} / \mathrm{C}$ Ratio menyatakan kelayakan suatu usaha apakah menguntungkan, impas atau suatu usaha dapat dikatakan mengalami kerugian.

Secara sistematis (R/C) dapat dirumuskan sebagai berikut. 
Volume VIII, No. 01, September 2019

$\mathrm{R} / \mathrm{C}$ Rasio $=\mathrm{TR} / \mathrm{TC}$

Keterangan : $\quad \mathrm{TR}=$ Total Revenue

$$
\mathrm{TC}=\text { Total Cost }
$$

Kriteria berdasarkan R/C Ratio adalah :

$\mathrm{R} / \mathrm{C}$ ratio $>1$, usaha budidaya padi sawah layak untuk diusahakan

$\square \mathrm{R} / \mathrm{C}$ ratio $=1$, maka usaha budidaya padi sawah tidak untung dan tidak rugi

$\square \mathrm{R} / \mathrm{C}$ ratio $<1$, usaha budidaya padi sawah tidak layak untuk diusahakan . (Firdaus, 2008).

\section{HASIL PENELITIAN DAN PEMBAHASAN}

\section{Geografis Wilayah Penelitian}

Desa Kuala Mulia adalah salah satu Desa yang terletak di Kecamatan Kuala Cenaku dan luas Desa $\pm 2.353,5$ Ha. Adapun perbatasan wilayahnya adalah :

$\checkmark$ Sebelah Utara batasnya dengan Sungai Indragiri

Sebelah Selatan batasnya dengan Desa Penyaguan Kecamatan Batang Gansal

Sebelah Timur batasnya dengan Desa Bayas Jaya

Sebelah Barat batasnya dengan Desa Kuala Cenaku

Desa Kuala Mulia ini termasuk kategori Daerah Pasang Surut.

\section{Luas Lahan Sawah Di Wilayah Penelitian}

Luas lahan merupakan factor yang mempengaruhi pendapatan petani padi sawah. Berdasarkan dari hasil penelitian penulis di Desa Kuala Mulia dimana kelompok petani padi terdiri dari 18 belas kelompok petani dengan luas lahannya adalah $410 \mathrm{H}$.

\section{Analisis Pendapatan Usahatani Padi Sawah}

1) Biaya Produksi

Biaya produksi adalah semua biaya atau modal baik yang dibayar tunai maupun yang tidak dibayar tunai selama proses produksi berlangsung. Biaya tunai adalah biaya yang dikeluarkan secara nyata dalam memproduksi padi sawah, seperti membeli sarana produksi (bibit, pupuk, pestisida dan lain sebagainya), alat-alat pertanian dan upah tenaga kerja dari dalam dan luar keluarga. Biaya tidak tunai yaitu biaya yang tidak dikeluarkan secara langsung tetapi diperhitungkan, biaya tidak tunai dalam penelitian ini adalah upah tenaga kerja dalam keluarga dan sewa tanah sawah (Hermanto, 1993). 
Harga jual padi, luas lahan dan jumlah biaya usaha tani berpengaruh terhadap jumlah produksi. Luas lahan, harga jual, Jumlah produksi berpengaruh terhadap pendapatan petani (Phahlevi. R, 2013).

Penggunaan biaya produksi dengan luas rata- rata lahan $1 \mathrm{Ha}$ pada usahatani padi sawah di Desa Kuala Mulia Kecamatan Kecamatan Kuala Cenaku seperti berikut ini.

Tabel 4.3 : Biaya Usahatani Padi rata-rata luas lahan 1 Ha di Desa Kuala Mulia.

\begin{tabular}{|c|c|c|c|c|}
\hline No. & Nama & Harga Satuan & $\begin{array}{r}\text { Total } \\
\text { Volume (Rp/Kg) } \\
\end{array}$ & Harga (Rp \\
\hline 1. & $\begin{array}{l}\text { Belaya Produksi : } \\
\text { a.Benih } \\
\text { b.Pupuk NPK Ponska } \\
\text { c.Moluskisida } \\
\text { d.Rolkutisida } \\
\text { e.Insektisida }\end{array}$ & $\begin{array}{c}25 \mathrm{Kg} \\
50 \mathrm{Kg} \\
250 \mathrm{Gr} \\
1 \mathrm{Kg} \\
2 \mathrm{Liter} \\
\end{array}$ & $\begin{array}{r}4.500 \\
2.300 \\
23.000 \\
45.000 \\
80.000 \\
\end{array}$ & $\begin{array}{c}112.500 \\
115.000 \\
92.000 \\
45.000 \\
160.000 \\
\end{array}$ \\
\hline 2. & $\begin{array}{l}\text { Bahan : } \\
-\quad \text { Goni/Karung }\end{array}$ & 100 Buah & 3.000 & 300.000 \\
\hline & Jumlah & & & 824.500 \\
\hline
\end{tabular}

Sumber : Data olahan 2019

Berdasarkan Tabel 4.3, luas lahan padi sawah untuk $1 \mathrm{Ha}$, maka jumlah biaya produksi adalah sebesar $\mathrm{Rp}$ 824.500. berarti secara keseluruhan adalah Rp.824.500,- $\mathrm{x} 410=$ Rp.338.045.000,-

Sedangkan biaya tenaga kerja yang mesti dikeluarkan untuk luas lahan 1 Ha dapat disimak pada tabel berikut ini.

Tabel 4.4. : Biaya Tenaga Kerja untuk luas lahan $1 \mathrm{Ha}$

\begin{tabular}{|c|c|c|}
\hline No. & Keterangan & Jumlah Belaya (Rp) \\
\hline 1. & Mengolah tanah & 800.000 \\
\hline 2. & Bertanam padi & 1.800 .000 \\
\hline 3. & Bersiang & 80.000 \\
\hline 4. & Memupuk & 80.000 \\
\hline 5. & Pengendalian Hama dan Penyakit & 80.000 \\
\hline 6. & Pemanenan & 2.000 .000 \\
\hline \multirow[t]{2}{*}{7} & Pasca panen & 800.000 \\
\hline & Jumlah & 5.640 .000 \\
\hline
\end{tabular}

Sumber : Petani Responden 2019 
Berdasarkan Tabel 4.4, biaya tenaga kerja yang yang seharusnya adalah sebesar Rp5.640.000,- /Ha. Berarti secara keseluruhan adalah sebesar Rp.5.640.000,- $\mathrm{x} 410=$ Rp.2.312.400.000,-.

2) Produksi dan Harga Jual

Jumlah produksi padi sawah rata - rata nilai produksi dan harga jual/kg diterima petani padi daerah Desa Kuala Mulia dapat dilihat berikut ini.

Tabel 4.5: Luas Lahan dan Harga Jual Padi Sawah/Kg di Desa Kuala Mulia, Tahun 2018

\begin{tabular}{|c|c|c|c|}
\hline Luas Lahan & Harga jual $(\mathrm{Rp} / \mathrm{Kg})$ & Produksi $(\mathrm{Kg})$ & Penerimaan $(\mathrm{Rp})$ \\
\hline $410 \mathrm{Ha}$ & $4.500,--$ & 1.435 .000 & 6.457 .500 .000 \\
\hline
\end{tabular}

Sumber : Data olahan 2019

Berdasarkan Tabel 4.5, luas lahan secara keseluruhan adalah $410 \mathrm{Ha}$ dengan hasil rata-rata 3.500, sehingga mencapai $1.435 .000 \mathrm{~kg}$ X Rp.4.500, = Rp. 6.457.500.000.

3. Pendapatan/Keuntungan

Adapun pendapatan usahatani budidaya padi sawah di daerah penelitian di Desa Kuala Mulia Kecamatan Kuala Cenaku Tahun 2018.

Tabel 4.6. Keuntungan dari usahatani padi sawah Desa Kuala Mulia Tahun 2018.

\begin{tabular}{|c|l|c|c|c|}
\hline $\begin{array}{c}\text { Luas } \\
\text { Lahan }\end{array}$ & Penerimaan & $\begin{array}{c}\text { Biaya } \\
\text { Produksi }\end{array}$ & Biaya Tk & $\begin{array}{c}\text { Keuntungan } \\
\text { Produksi } \\
\text { (Rp) }\end{array}$ \\
\hline 410 & 6.457 .500 .000 & 338.045 .000 & 2.312 .400 .000 & 3.807 .055 .000 \\
\hline
\end{tabular}

Sumber : Data olahan 2019

Dari Table 4.6 diperoleh keuntungan petani padi sawah di Desa Kuala Mulia adalah sebesar Rp.3.807.055.000.

Berdasarkan hasil Wawancara dengan petani diperoleh bahwa lahan di Desa Kuala Mulia selalu basah. Karena daerah sini adalah daerah pasang surut. Yang sangat menguntungkan bagi para petani. 


\section{Analisis R/C Rasio}

Dari hasil perhitungan (R/C Rasio) didapatlah nilainya seperti berikut :

$\mathrm{TR}=6.457 .500 .000,-$

$\mathrm{TC}=338.045 .000+2.312 .400 .000=2.650 .445 .000$

$\mathrm{R} / \mathrm{C}$ Rasio $=6.457 .500 .000 / 2.650 .445 .000=2,443$

Berdasarkan perhitungan di atas, dapat diketahui jika penerimaan yang diperoleh petani di Desa Kuala Mulia Rp 6.457.500.000,- dan biaya total yang harus dikeluarkan petani sebesar Rp 2.650.445.000,- maka nilai R/C Rationya sebesar 2,443 yang berarti, setiap Rp 1 petani mengeluarkan biaya usahatani padi sawah maka akan diperolehnya keuntungan Rp 2,443. Dengan demikian R/C Ratio lebih besar dari 1 (R/C > 1) maka dengan demikian usahatani lebih layak untuk diusahakan.

\section{KESIMPULAN DAN SARAN}

\section{Kesimpulan}

Kesimpulan yang dapat diambil dari hasil penelitian ini adalah sebagai berikut :

1. Besar kecilnya penerimaan petani sangat tergantung dari harga jual gabah, hasil pruduksinya, kemudian juga biaya produksi. Semakin tinggi Harga jual gabah dan semakin tinggi hasil produksinya maka penerimaan petani akan meningkat. Dan semakin tinggi biaya produksi maka penerimaan petani akan semakin menurun.

2. Dari hasil penelitian ini diperoleh bahwa, Jika luas dari lahan pertanian adalah $1 \mathrm{Ha}$, dan biaya produksinya adalah $\mathrm{Rp} 824.500$,- serta biaya tenaga kerjanya adalah $\mathrm{Rp}$ 5.640.000,- , hasil penjualan gabah adalah sebesar Rp.4.500,- $\mathrm{x} 3.500 \mathrm{Kg}=$ Rp.15.750.000.-/Ha.

3. Dari hasil penelitian ini diperoleh, penerimaan petani padi sawah di Desa Kuala Mulia adalah Rp6.457.500.000,- sedangkan biaya produksi dan tenaga kerja adalah Rp2.650.445.000,- maka akan diperoleh keuntungan sebesar Rp.3.807.055.000,-.

4. Dari hasil penelitian dapat diperoleh $\mathrm{R} / \mathrm{C}$ ratio adalah 2,443. Artinya, Usahatani padi sawah di Desa Kuala Mulia layak untuk dikembangkan. 


\section{Saran-saran}

1. Diharapkan harga jual gabah tidak mengalami penurunan dan hasil produksi meningkat dan biaya produksi juga tidak mengalami kenaikan, agar pendapatan petani tidak menurun.

2. Diharapkan para petani padi sawah di Desa kuala mulia bisa dengan menambah luas lahannya. Karena jika luas lahannya bertambah maka hasil pertanian akan meningkat. Dan dengan meningkatnya hasil pertanian diharapkan pendapatan petani padi sawah juga akan meningkat.

3. Kepada para petani di Desa Kuala Mulia diharapkan untuk menambah pengetahuan, kemudian harus dapat mengambil inovasi - inovasi baru tentang pertanian sehingga dapat mempengaruhi produksi dan pendapatan lebih meningkat sehingga lebih mensejahterakan keluarga dan masyarakatnya.

4. Selaku mitra kerjanya petani, diharapkan kepada penyuluh pertanian lapangan agar lebih meningkatkan kunjungannya pada kelompok tani di Desa Kuala Mulia, sehingga lebih cepat mengetahui permasalahan apa yang sedang dihadapi oleh petani, dan memberikan solusi yang tepat terhadap permasalahan yang dihadapi petani.

\section{REFERENCE}

Arsyad, (2004), Medis Pembelajaran, Raja Grafindo Persada, Jakarta.

Chonani, dkk (2014), Efisiensi Produksi dan pendapatan Usaha tani Cabai Merah di Kecamatan Metro Kibang Kabupaten Lampung Timur : Pendekatan Fungsi Produksi Frontier, Jurnal Agribisnis, volume 2, No.2, 95

Dumairy, 2004, Matematika Terapan Untuk Bisnis dan Ekonomi, BPFE, Yogyakarta

Fatmawati, M.L, (2013), Analisis Pendapatan di Desa Teep Kecamatan Langowan Timur, Dalam Jurnal EMBA. Vol. 1. No. 3 September 2013, Hal. 991 - 998.

Firdaus, Muhammad, (2008), Managemen Agribisnis, Bumi Aksara, Jakarta.

Haryanto, Tri dkk (2009), Ekonomi Pertanian, Cet. 1 - Airlangga University Press, Surabaya.

Hermanto, Bambang, (1993), Analisa Laporan Keuangan, Lentera Ilmu Cendekia, Jakarta. 
Hutabarat, B, 1995, Pengukur Dampak Nilai Tukar terhadap Produksi Dan Pendapatan Petani, Jurnal Agro Ekonomi, Pusat Penelitian Sosial Ekonomi Pertanian, Departemen Pertanian, Jakarta.

Jhingan, ML, (2003), Ekonomi Pembangunan dan Perencanaan, Raja Grafindo, Jakarta.

Phahlevi, R (2013) Faktor-faktor yang mempengaruhi pendapatan petani padi sawah di Kota Padang Panjang, Dalam skripsi Program studi Ekonomi Pembangunan, Fakultas Ekonomi, Universitas Negeri Padang.

Rahardjo, P, 2001, Teori Ekonomi Makro Suati Pengantar, UI Press, Jakarta.

Rosyidi, S, 1998, Pengantar Teori Ekonomi Pendekatan Kepada Teori Ekonomi Mikro dan Makro, Radja Grafindo, Jakarta.

Soekartawi, dkk (2002), Ilmu Usahatani, Universitas Indonesia, UI Press, Jakarta.

Soekartawi, (2010), Agribisnis dan Aplikasi, Rajawali Pers, Jakarta.

Sugiyono, (2010), Statistika Untuk Penelitian, Alfabeta, Bandung.

Sunyoto, Danang, 2011, Matematika Ekonomi Dan Bisnis, Caps, Yogyakarta.

Suratiyah Ken, (2015), Ilmu Usahatani, Penebar Swadaya.Jakarta.

Suryana, A, 2003, Kapita Selekta Evolusi Pemikiran Kebijakan Ketahanan Pangan. Edisi 03/04, BPFC, Yogyakarta.

Wisma, 2012, Karakteristik Fungsi Produksi Usahatani Pangan di Indonesia, Jurnal Ilmiah Edukasi Volume 2 Nomor 12 Tahun ke lima, Jakarta. 